\title{
DIREITO À VIDA PRIVADA E DIREITO À INFORMAÇÃO: COLISÃO DE DIREITOS FUNDAMENTAIS ${ }^{1}$
}

\author{
Régis Schneider Ardenghi
}

Resumo: Este artigo aborda a problemática do direito à vida privada e do direito à informação. Seu objetivo é examinar esses direitos à luz da Constituição da República Federativa do Brasil de 1988, buscando um consenso para as discussões que cercam esses dois princípios fundamentais tutelados no mesmo nível constitucional. O texto construído com base no estudo sobre o "Direito à vida privada e informação jornalística", 2 utilizando pesquisa bibliográfica, procurou mostrar o direito à vida e à informação como direitos fundamentais e o conflito entre esses direitos. Os resultados do estudo indicaram que a solução para o conflito entre o direito à vida privada e o direito à informação deve ser buscada no ordenamento jurídico brasileiro e na interpretação das normas constitucionais.

Palavras-chave: Colisão de direitos. Vida privada. Informação.

\section{INTRODUÇÃO}

O tema direito à vida privada e direito à informação tem como foco o conflito existente entre esses dois princípios

1 ARDENGHI, Régis Schneider. Direito à vida privada e informação jornalística. [dissertação], Curso de Pós-Graduação Stricto Sensu em Ciência Jurídica - Mestrado. Universidade do Vale do Itajaí, SC. Itajaí, 2002.

2 Graduado pela Pontifícia Universidade Católica de Porto Alegre - RS - PUCRS. Mestre em Ciência Jurídica pela Universidade do Vale do Itajaí - UNIVALI. Advogado e Professor de Direito Civil na Escola Superior da Magistratura do Estado de Santa Catarina - ESMESC e na Universidade do Sul de Santa Catarina - UNISUL. E-mail: regisardenghi@hotmail.com. 
constitucionais, e objetiva esclarecer a questão da colisão entre esses direitos. A liberdade de imprensa, consubstanciada na informação jornalística como apanágio dos Estados democráticos, enseja a verificação de como o Estado pode contornar o problema do acelerado desenvolvimento dos meios de informação e a invasão da privacidade, servindo de instrumento para o desrespeito a Direitos Humanos fundamentais. Nesse contexto, pretende-se identificar qual desses direitos deve preponderar: o direito à vida privada ou à liberdade de imprensa?

Diante da latente tensão entre o direito à vida privada e à liberdade de imprensa, cuja complexidade do tema, na sociedade contemporânea, traz como marca o pluralismo de valores, a informação como um bem transacionável e a transformação na atuação dos jornalistas. Percebe-se que o conteúdo do direito à vida privada só pode ser estabelecido a partir dos valores sociais vigentes, que determinam o que cada pessoa tem para guardar para si mesma, o que interessa manter sob reserva. Somente uma análise mais ampla do direito à vida privada pode indicar quando a imprensa comete invasão de privacidade e quando a proteção da vida privada deve ser acolhida ou não.

No Brasil, a Carta Constitucional, os Códigos, as leis e altas autoridades são vocacionadas para arbitrar conflitos. Mas, diante dos paradoxos existentes, um enfoque sociológico-jurídico abre caminho para as questões controversas. No plano técnico, utiliza-se a abordagem indutiva, com apoio na pesquisa bibliográfica. Os tópicos principais focalizam o direito à vida privada e à informação como direitos fundamentais e o conflito entre esses direitos.

\section{DIREITO À VIDA PRIVADA E À INFORMAÇÃO COMO DIREITOS FUNDAMENTAIS}

Contra o individualismo extremo existente no século XIX, no século XX foram sendo reconhecidos direitos em favor dos grupos sociais e do indivíduo, como o direito de associação como garantia da própria liberdade individual. 
As manifestações dessa nova concepção ocorreram nas primeiras constituições republicanas, sendo a mais famosa delas a de Weimar, de 1919. Por essa época, os direitos individuais já extrapolavam os limites de cada Estado, sendo proclamados direitos transnacionais.

Do ponto de vista histórico, na dimensão empírica, os direitos fundamentais são, originalmente, direitos humanos (GUERRA FILHO, 2003). No esteio da melhor doutrina, os direitos fundamentais resultam em posições jurídicas das pessoas enquanto tais, com eficácia no âmbito das relações com o Estado ou entre particulares, consubstanciadas ou não na Constituição.

Alexandre Moraes (2009, p.39) define os direitos humanos fundamentais como "[...] o conjunto institucionalizado de direitos e garantias do ser humano que tem por finalidades básicas o respeito a sua dignidade, por meio de sua proteção contra o arbítrio do poder estatal e o estabelecimento de condições mínimas de vida e desenvolvimento da personalidade humana $[\ldots] "$.

José Castan Tobeñas, por sua vez, define direitos humanos como aqueles direitos fundamentais da pessoa humana - tanto individual como comunitários - que correspondam a essa em razão de sua própria natureza (essência espiritual, corpórea e social) e que devem ser reconhecidos e respeitados por todo poder e autoridade, inclusive as normas jurídicas positivas, cedendo, no entanto, em seu exercício, ante as exigências do bem comum (apud MORAES, 2000).

Os direitos humanos relacionam-se diretamente com a garantia de não ingerência do Estado na esfera individual e a consagração da dignidade humana.

A existência de inúmeros e diferenciados conceitos de direitos fundamentais, definidos como direitos humanos fundamentais, torna difícil estabelecer-lhes um conceito que envolva toda sua significação. Para José Afonso da Silva (2011, p. 175): 
[...] a ampliação e transformação dos direitos fundamentais do homem no envolver histórico dificulta definir-lhes um conceito sintético e preciso. Aumenta essa dificuldade a circunstância de se empregarem várias expressões para designá-los, tais como: direitos naturais, direitos humanos, direitos do homem, direitos individuais, direitos públicos subjetivos, liberdades fundamentais, liberdades públicas e direitos fundamentais.

Pela abrangência, esses direitos colocam-se em elevada posição hermenêutica em relação aos demais direitos previstos no ordenamento jurídico e apresentam um feixe de características: imprescritibilidade; inalienabilidade; irrenunciabilidade; inviolabilidade; universalidade; efetividade; interdependência; e complementaridade.

Várias classificações dos direitos fundamentais têm sido erigidas pelos doutrinadores. Deixando de lado a análise das dimensões e o aprofundamento conceitual delas, estuda-se a classificação que os categoriza em gerações, como o faz Bobbio (2004).

Segundo o mesmo autor, sem os direitos do homem reconhecidos e protegidos, não há democracia; sem essa, não existem as condições mínimas para a solução pacífica dos conflitos. Basta examinar os escritos dos primeiros jusnaturalistas para ver quanto se ampliou a lista dos direitos. Hobbes conhecia apenas um deles, o direito à vida. Hoje são conhecidos vários direitos e já se caminha para a quinta geração.

A declaração contida na Constituição Brasileira de 1988 é a mais abrangente de todas as anteriores e, além de consagrar os "direitos e deveres individuais e coletivos", abre um capítulo para definir os direitos sociais. Não enumera os direitos fundamentais, admite existir outros decorrentes do regime e dos princípios por ela adotados.

Uma breve análise da classificação que adota a expressão "geração" de direitos aponta que os direitos civis (primeira geração) surgiram com as declarações de direitos de 1776 e de 
1789, sendo integrados pelos "direitos negativos", estabelecidos contra o Estado. Esses direitos determinam a divisão entre a esfera pública (Estado) e a esfera privada (sociedade civil). A diferença entre essas esferas é uma das características fundamentais da sociedade moderna. É a partir dessa distinção que se estrutura o pensamento liberal e o pensamento democrático.

Tendo como titular o indivíduo, os direitos de primeira geração são oponíveis ao Estado e traduzidos como atributos da pessoa humana, ostentando uma subjetividade que é seu traço marcante. São os direitos de resistência face ao Estado, e entram na categoria do status negativus da classificação de Jellinek (BONAVIDES, 2004). Entre esses direitos situam-se: as liberdades físicas, as liberdades de expressão, as liberdades de consciência, as liberdades de propriedade privada, os direitos da pessoa acusada, e as garantias dos direitos.

Os direitos políticos (segunda geração) surgiram no decorrer do século XIX. São positivos, ensejam os direitos de participar no Estado e mostram o surgimento de uma nova perspectiva da liberdade, como autonomia; com liberdade de participar da formação do poder político. Os principais direitos políticos são: o direito ao sufrágio universal, de construir partidos políticos, e de plebiscito, de referendo e de iniciativa popular.

No início do século XX, surgiram os direitos econômicos e sociais (terceira geração) e abrangem os denominados "direitos de créditos", que tornam o Estado devedor dos indivíduos. Referem-se à obrigação do Estado de realizar ações concretas, visando a garantir-lhes um mínimo de igualdade e de bem-estar social, fazendo ressurgir o princípio da igualdade.

Celso Lafer (1988) vê na convergência entre as liberdades clássicas e os direitos de créditos a viabilidade da democracia no mundo contemporâneo. Por sua vez, Silva (2011) apresenta os direitos econômicos e sociais divididos como direitos relativos ao homem trabalhador e os direitos relativos ao homem consumidor. 
Diante de um quadro realista, os direitos de terceira geração são identificados como o direito ao desenvolvimento, o direito à paz, o direito ao meio ambiente, o direito de propriedade sobre o patrimônio comum da humanidade e o direito de comunicação (BONAVIDES, 2004).

Os sujeitos desses direitos são os grupos de indivíduos, como a família, o povo, a nação e a própria humanidade (BOBBIO, 2004).

Para tornar possível e viável o desenvolvimento desses direitos, há um cenário reservado à quarta geração de direitos (direito à democracia, direito à informação e direito ao pluralismo), que correspondem à derradeira fase de institucionalização do Estado social.

Os direitos de solidariedade (quarta geração) têm como grande marco o ano de 1948 e compreendem os direitos do homem no âmbito internacional, como direitos sobre o Estado. Opera-se novo deslocamento do lugar dos direitos diante do Estado, de por "meio" do Estado para "sobre" o Estado, apontando uma mudança no conceito de soberania. A soberania não é mais compreendida na forma absoluta, como no início da Idade Moderna, passa a ser pensada de forma integrada e coordenada por um sistema de jurisdição internacional.

Os Estados particulares passam a realizar ações articuladas e orientadas, formando os grandes blocos econômicos, sociais e políticos. Os indivíduos singulares e os grupos sociais se desnacionalizam, surgem as declarações, as cartas e os pactos internacionais de proteção dos indivíduos, grupos sociais e humanidade fora do âmbito dos Estados, no marco da Declaração Universal dos Direitos do Homem de 1948.

Entre os direitos de solidariedade colocam-se as seguintes prerrogativas: direito ao desenvolvimento, ao meio ambiente sadio, à paz, à autodeterminação dos povos. Deles depende a materialização da sociedade aberta do futuro, em sua dimensão de máxima universalidade, para a qual parece o mundo quedar-se no plano de todas as afinidades e relações de coexistência. 
Enquanto direito de quarta geração, a democracia positivada deve caminhar para uma democracia direta, possibilitada pelos avanços tecnológicos dos meios de comunicação, e sustentada legitimamente pela informação correta e aberturas pluralistas do sistema (BONAVIDES, 2004). Uma democracia isenta das contaminações e manipulação da mídia, pois essa geração de direitos não somente culmina a objetividade dos direitos das duas gerações antecedentes, como absorve a subjetividade dos direitos individuais, de primeira geração.

Para além dessas classificações, Schmitt (1996) estuda os direitos fundamentais estabelecendo dois critérios formais e um critério material de caracterização. Dessa perspectiva, pelo primeiro critério formal, indica como direitos fundamentais todos os direitos e garantias explicitados e alcunhados no documento constitucional; e pelo segundo critério formal, os direitos fundamentais são aqueles que recebem da constituição um grau mais elevado de proteção, ou segurança, ou pelo menos de alteração dificultada.

Do ponto de vista material, os direitos fundamentais variam de Estado para Estado, dependendo de sua ideologia, de sua forma, ou seja, cada Estado com sua especificidade de direitos. Percebe-se em Schmitt (1996), que o autêntico direito fundamental do indivíduo é sempre absoluto e corresponde ao princípio de distribuição do Estado de Direito, segundo o qual a liberdade do indivíduo é ilimitada em princípio, e a faculdade do Estado limitada em princípio. Dessas condições de absoluto e de ilimitado em princípio, não se segue à impossibilidade absoluta de ingerência e limitações, porém, elas aparecem como exceção, calculadas, mensuráveis e controláveis, por isso só podem ter lugar à base de leis, no conceito próprio do Estado de Direito, como uma norma geral. $O$ direito fundamental e de liberdade se encontra, pois, sob a salvaguarda da lei.

A Constituição brasileira reconhece e assegura direitos fundamentais explicitamente no art. $5^{\circ}$, direitos cujo objeto imediato é a liberdade: de locomoção, de pensamento, de 
reunião, de associação, de profissão, de ação, liberdade sindical, direito de greve, direitos cujo objeto imediato é a segurança: dos direitos subjetivos em geral, em matéria penal (presunção de inocência), do domicílio; direitos cujo objeto imediato é a propriedade: propriedade em geral, artística, literária e científica.

Aparentemente, não há problemas na evolução dos direitos. Ao redor do núcleo essencial dos direitos liberais se dá uma contínua agregação de direitos que, sem ferir os princípios inspiradores fundamentais, vem ampliando o leque dos direitos possíveis, acompanhando o crescimento da "consciência mundial" da humanidade. Mas, a realidade mostra complexidades, porque atrás da lista crescente de direitos existem concepções diferentes de homem e de sociedade, que não são facilmente compatíveis.

A moderna doutrina constitucional, ressalvadas exceções, vem rechaçando a utilização de termos como liberdades públicas, liberdades fundamentais, direitos individuais e direitos públicos subjetivos, direitos naturais e direitos civis, assim como as suas variações, porque estão, de certa forma, divorciados do estágio atual da evolução dos direitos fundamentais no âmbito de um Estado (democrático e social) de Direito ${ }^{3}$. Até mesmo em nível internacional, esses direitos revelam insuficiência quanto à sua abrangência, por estarem atrelados a categorias específicas do gênero direitos fundamentais (SILVA apud SARLET, 2011).

A busca do direito que deve preponderar, se o direito à vida privada ou o direito à informação quando surgem conflitos entre eles, exige uma explicação sobre esses direitos fundamentais.

3 "Deve-se atentar para o fato de que algumas Constituições do segundo pós-guerra passaram a utilizar a expressão genérica 'direitos fundamentais', tais como a Lei Fundamental da Alemanha (1949) e a Constituição Portuguesa (1976), bem como as Constituições da Espanha (1978), da Turquia (1982) e da Holanda (1983)", assevera Sarlet (2011). 


\subsection{Direito à vida privada}

A vida privada, como direito, decorre da personalidade, e faz parte do direito à vida, constituindo-se em tema de importância atual, dada a preocupação em se buscar maior proteção e efetividade aos direitos individuais. Como todos os direitos gravitam em torno do direito à vida, é importante ter presente que a Carta Magna lhe atribui especial relevo jurídico, proclamando-o imperativo fundamental da convivência social.

Segundo Silva (2011, p. 198), "[...] a vida humana, que é o objeto do direito assegurado no art. 5, caput, da Constituição Federal de 1988, integra-se de elementos materiais (físicos e psíquicos) e imateriais (espirituais)". Isso faz com que a vida tenha intimidade conosco mesmo (caracterizado no dar-se conta de si mesma, no assistir a si mesma e no tomar posição sobre si mesma). Por isso, a vida humana constitui a fonte primária de todos os outros bens jurídicos. No conteúdo do seu conceito encontra-se o direito à existência, à dignidade da pessoa humana, ao respeito, à integridade físico-corporal e moral, e à privacidade.

Silva usa a expressão "direito à privacidade" em sentido genérico amplo, englobando todas as manifestações da esfera íntima, privada e da personalidade (ARAÚJO, 1998, p. 44). A privacidade é definida como um "[...] conjunto de informações acerca do indivíduo que ele pode decidir manter sob seu exclusivo controle, ou comunicar, decidindo a quem, quando, onde e em que condições, sem a isso poder ser legalmente sujeito". Esse seria o traço característico da tutela à privacidade das pessoas, em seu sentido lato. Na lição de Bittar (2004), cuida-se de garantir a "[...] elisão de qualquer atentado a aspectos particulares ou íntimos da pessoa, em sua consciência, ou em seu circuito próprio, compreendendo-se o seu lar, a sua família e a sua correspondência”, e em alguns casos até o patrimônio.

O direito à vida privada, como espécie dos direitos da personalidade, requer a compreensão do que se expressa por direitos da personalidade. 
Em sentido jurídico, a personalidade tem sido concebida como aptidão para ser sujeito de direitos e obrigações no mundo jurídico. Toda pessoa humana tem essa aptidão, de acordo com todos os sistemas jurídicos, no estágio atual da civilização. De acordo com Daniel Coelho (apud, FERREIRA DA SILVA, 2003, p. 6):

[...] os chamados direitos personalíssimos ou direitos de personalidade são esses direitos que integram a própria noção de pessoa, como a vida, a honra, a integridade física, a imagem, a privacidade etc. Menciona ser a ordem jurídica que confere aos entes a qualidade de pessoa, dotando-os de personalidade jurídica, ou seja, da virtualidade de ser sujeito de direitos e de obrigações, e que isso de nada valeria se ao mesmo tempo não lhes assegurasse um mínimo de direitos como condição indispensável à aquisição de todos os demais direitos.

O homem ao adquirir direitos e assumir obrigações passa a responsabilizar-se por todos os atos e fatos que envolvem sua vida. A personalidade como conjunto de caracteres próprios da pessoa física e jurídica não se reveste de direito, mas de objeto do direito, atributos da pessoa, como nome, honra, liberdade, intimidade (AMORIM, 1998).

Os direitos da personalidade são direitos personalíssimos, essenciais à pessoa humana, e garantidores de toda a esfera individual. Segundo definição de Bittar (2004), são aqueles direitos essenciais, vitalícios e intransmissíveis, em regra, necessários e oponíveis erga omnes ${ }^{4}$, que têm posição singular no âmbito dos direitos privados, por protegerem valores inatos, ou originários, da pessoa humana e, também, da pessoa jurídica, como a vida, a honra, a identidade, o segredo e a liberdade.

4 "Nos direitos da personalidade, a pessoa, é, a um só tempo, sujeito e objeto de direitos, remanescendo a coletividade, em sua generalidade, como sujeito passivo; daí, dizer-se que esses direitos são oponíveis erga omnes (e, portanto, devem ser respeitados por todos os integrantes da coletividade). Trata-se, pois, de relação de exclusão, que impõe a todos a observância e o respeito a cada pessoa, em seus componentes (atributos físicos, psíquicos e morais, projeções sociais), sob pena de sancionamento do ordenamento jurídico" (BITTAR, 2004). 
O autor não inclui nesta classificação o direito à vida privada, certamente por considerá-lo como direito à intimidade. Todavia, no exame atento dessas figuras jurídicas, nota-se que cada uma delas demonstra particularidades próprias, esse é o entendimento da Constituição Federal de 1988, ao separar a intimidade de outras manifestações da privacidade (vida privada), honra e imagem das pessoas (art. 50, inc. X). ${ }^{5}$

Ingo Wolfrang Sarlet (2011), apreciando a extensão do conceito de privacidade, feita pela Corte Européia de Direitos Humanos, no caso Niemitz v. Germany, em 1992, entende que:

[...] seria muito restritivo limitar a noção [de 'vida privada'] a um 'círculo interior' no qual o indivíduo possa viver sua vida pessoal como ele quiser e excluir inteiramente daí o mundo exterior não incluído neste círculo. $\mathrm{O}$ respeito pela vida privada deve compreender em certo grau o direito de estabelecer e desenvolver relacionamentos com outros seres humanos. ${ }^{6}$

Quanto ao conceito de intimidade, de caráter mais restritivo que da vida privada, seria a essência dessa, enquanto o direito à intimidade, como decorrência do direito à vida privada, seria o direito de estar só, de ter direito ao segredo (em situações constrangedoras ou embaraçosas que possam denegrir a imagem), à reserva e à tranquilidade interiores (ARAÚJO, 1998).

Invoca-se o respeito devido à individualidade, em virtude da cláusula constitucional da dignidade da pessoa humana (art. $1^{\circ}$, inc. III, CF). A dignidade da pessoa humana é elemento central na sociabilidade que caracteriza o conceito de Estado Democrático de Direito, que promete aos indivíduos muito mais que abstenção de invasões ilegítimas de suas esferas pessoais, a promoção positiva de suas liberdades.

5 Art. $5^{\circ}$, inc. X - "São invioláveis a intimidade, a vida privada, a honra e a imagem das pessoas, assegurado o direito à indenização pelo dano material ou moral decorrente de sua violação".

6 Apreciação feita pela Corte Européia de Direitos Humanos, do caso Niemitz v. Germany (1992). Tradução de Roger Raupp Rios (SARLET,2011). 
O direito da personalidade tem como objetivo primordial assegurar a integridade das pessoas em qualquer campo da vida $\mathrm{e}$ do relacionamento humano. Representam, esses direitos, verdadeiras muralhas antepostas pelo direito como defesa da pessoa frente a invasões de qualquer outro componente da coletividade (AMORIM, 1998).

Os direitos do homem são direitos públicos, assim como os direitos da personalidade são direitos privados. Esse parece ser um posicionamento unânime da doutrina, que faz tal distinção entre os chamados direitos humanos (aspecto público) e os da personalidade (aspecto privado). O que marca os direitos de personalidade como uma categoria jurídica autônoma é a sua tríplice configuração como direitos privados, não patrimoniais e absolutos (FERREIRA DA SILVA, 2003).

Como direito de personalidade, o direito à intimidade é geral porque assiste a todas as pessoas; vitalício porque acompanha a pessoa durante toda a sua existência; intransmissível, imprescritível, impenhorável e não sujeito à desapropriação porque não pode ser desvinculado de cada pessoa, dada sua condição de direito fundamental. É direito subjetivo privado porque confere às pessoas um poder em face dos seus semelhantes de se resguardar de intromissões e de publicidade na esfera mais reservada da existência, como também a faculdade de fazer concessões nesse terreno. Vale, então, destacar que uma certa dose de reserva e de recolhimento é de importância fundamental para o desenvolvimento saudável da personalidade, pois o desenvolvimento do sentimento de família e de infância só se desenvolveu nos séculos XVI e XVII, quando a família buscou, no restrito círculo familiar, motivos de vida em comum, e no cotidiano do lar, criou espaços privados de convivência, adquirindo consciência de espaço privado e público, e gosto pela vida isolada.

O direito à intimidade se destina a resguardar a privacidade em seus múltiplos aspectos: pessoais, familiares e negociais (BITTAR, 2004). Esse direito tem recebido diferentes denomi- 
nações: "direito de estar só"; "direito à privacidade" e "direito ao resguardo", e consubstancia-se em mecanismo de defesa da personalidade humana contra injunções, indiscrições ou intromissões alheias. Embora tenha encontrado na doutrina dimensionamentos diversos, tornando difícil definir seu conteúdo, nele divisa-se a proteção à privacidade, na medida exata da elisão de qualquer atentado a aspectos particulares ou íntimos da vida da pessoa, em sua consciência ou em seu circuito próprio, compreendendo-se o seu lar, a sua família e a sua correspondência.

Vem ganhando relevo, com a contínua expansão das técnicas de comunicação, como defesa natural do homem contra as investidas tecnológicas e a ampliação, com a necessidade de locomoção do circuito relacional do homem, obrigando-o à exposição permanente perante públicos os mais distintos, em seus diferentes trajetos sociais, negociais ou de lazer. Limita-se, com o direito à intimidade, o quanto possível, a inserção de estranho na esfera privada ou íntima da pessoa.

Inúmeros acontecimentos demonstram como pode ser preservada essa relação entre a vida pública e a privada e as dificuldades de se estabelecer os limites de uma e de outra, principalmente quando estão em questão pessoas com atuação pública relevante.

A imprensa vem interferindo arbitrariamente na vida privada, expondo as pessoas notórias, principalmente, nos aspectos familiares e pessoais, mesmo contra o desejo de que certos aspectos não cheguem ao conhecimento de terceiros. Todavia, não é demais lembrar que os famosos, tão pródigos em reclamar das invasões de privacidade de imprensa, também têm sua parcela de culpa na curiosidade mórbida da grande massa, estimulando a especulação sobre sua vida, também quando não querem.

A discussão vai mais além, engloba a contradição entre essência de função pública e política do serviço jornalístico e sua forma de organização na sociedade capitalista contempo- 
rânea. Mas, lembra-se, que no campo do direito à intimidade são protegidos, entre outros bens, confidências, informes de ordem pessoal (dados pessoais), recordações pessoais, memórias, diários, relações familiares, lembranças de família, sepultura, vida amorosa ou conjugal, saúde (física e mental), afeições, entretenimentos, costumes domésticos e atividades negociais, reservados pela pessoa para si e para seus familiares (ou pequeno círculo de amizade) e, portanto, afastados da curiosidade pública (BITTAR, 2004).

$\mathrm{Na}$ esfera privada propriamente dita, tem-se a pessoa em seu interior ou em sua intimidade (esfera da confidencialidade ou do segredo, reservada ao intelecto próprio) e, portanto, inatingível por ação arbitrária de terceiro. Sendo esses valores mutáveis no tempo e diferenciados em cada cultura e em cada lugar, o direito à vida privada e à intimidade terá, igualmente, um conteúdo múltiplo e variável, muitas vezes, um interpenetrando no plano do outro.

Ferreira da Silva (2003) entende que o direito à intimidade deve compreender o poder jurídico de subtrair ao conhecimento alheio e de impedir qualquer forma de divulgação de aspectos da vida privada, que segundo um sentimento comum detectável em cada época e lugar, interessa manter sob reserva.

A Constituição de 1988, ao resguardar a vida privada e a intimidade, assegurando a sua inviolabilidade (art. 5º inc. X), está reconhecendo que o homem tem direito fundamental a um lugar em que, só ou com sua família, gozará de liberdade nas relações familiares (a liberdade de viver junto sob o mesmo teto), as relações entre pais e seus filhos menores, as relações entre os dois sexos (a intimidade sexual). Não há dúvida que essa é uma esfera privada (note-se, não dir-se-ia íntima), pois a pessoa humana, no recesso do lar, tem protegida a liberdade de domicílio, o sigilo da correspondência, o segredo profissional, todavia, as análises pecam por amplitude.

O direito à intimidade é o direito de alguém poder recolher-se à solidão e ter seu universo íntimo preservado, porque 
nada mais é, segundo Pontes de Miranda, que "[...] um efeito do exercício da própria liberdade”, consistindo em fazer, ou deixar de fazer, o que melhor the aprouver (apud AIETA, 1999, p. 90).

Num Estado Democrático de Direito, onde há a preocupação em que as liberdades, o pluralismo e os direitos fundamentais sejam atendidos e efetivamente protegidos, a construção e a abertura de valiosas perspectivas de definição constitucional da privacy desenvolvem-se numa ambiência favorável. Nessa direção caminhou o legislador na elaboração do Código Civil Brasileiro de 2002, destinando os dois capítulos iniciais do Título I para tratar da personalidade.

Nessa construção, é subjacente que a intimidade está situada como um círculo mais restrito do direito à vida privada, mas nem por isso menos importante, como na análise da legislação infraconstitucional.

$\mathrm{O}$ direito à intimidade e à vida privada se apresentam como direito à liberdade (SAMPAIO, 1998). A liberdade gera responsabilidade e leva os transgressores dos direitos da personalidade, de pessoas notórias ou não, a arcarem com os danos morais e patrimoniais causados, além das sanções penais previstas. No uso do direito de liberdade, a pessoa vale-se de seu duplo sentido filosófico: de não intromissão e de autonomia (direito de escolha).

"A limitação ao direito à intimidade nasce quando os interesses do indivíduo são superados, em grau de prioridade, pelos interesses da coletividade" (AIETA, 1999, p. 165). Esse argumento encontra alicerce no princípio da supremacia do interesse público, daí ser freqüente, na atualidade, autorizações da Justiça sobre a divulgação de detalhes da vida íntima de pessoas públicas (políticos, artistas, delinqüentes), na defesa do interesse público. O universo de interseção entre as liberdades públicas e a tutela constitucional da intimidade é limitado pela finalidade primeira da Administração Pública.

O interesse público, no entanto, difere da chamada "curiosidade coletiva”. Hannah Arendt (apud AIETA, 1999, p. 166) 
adverte: "[...] um dos mais sérios problemas do direito contemporâneo, o fenômeno, [...], da publicização do Direito Privado e da privatização do Direito Público [...]” leva a identificar e a não diferenciar o que é esfera pública ou privada.

Entre as inúmeras causas excludentes do delito de indiscrição, o caso que melhor anula a violação ocorre com o consentimento do interessado, a vontade do indivíduo é soberana no universo da legalidade.

\subsection{Direito à informação}

O direito à informação tem suas origens na liberdade de imprensa, elevada à condição de norma constitucional pela Franca, em 1789, e pelos Estados Unidos, em 1791, na primeira emenda à Constituição americana (SERRANO, 1997).

O termo liberdade de imprensa foi cunhado em razão de, àquela época, somente existir o meio de comunicação impresso para divulgação pública da informação. Durante a era liberal, a imprensa era um prolongamento do direito de opinião, atuando como síntese das liberdades básicas e como instrumento de defesa contra o poder ilimitado do Estado. Com o surgimento de novas vertentes do pensamento moderno, a liberdade de expressão foi erigida a direito fundamental da pessoa humana. Entretanto, o exercício dessa liberdade pelos meios de comunicação, passou a sofrer restrições decorrentes do interesse individual, a par dos objetivos sociais da comunidade (DOTTI, 1990).

No Brasil, desde o tempo do Império, a liberdade de imprensa ultrapassou, com frequência, os limites relativos aos direitos da personalidade, mas foi a partir de 1950 que aumentaram os casos de invasão da intimidade das pessoas.

A liberdade de informação compreende tanto o direito à informação, que se confunde com a liberdade de manifestação do pensamento, tutelada pela Constituição Brasileira em seu art. 5, IV, como o direito de ser informado, que corresponde ao direito coletivo de receber a informação (CALDAS, 1997). A 
liberdade de pensamento, realçada como direito fundamental, nunca foi a tônica da história, tampouco a liberdade de informação, a sua contraface, o foi. Assim, embora seja um direito consagrado nos regimes democráticos e a própria história tenha se encarregado de revelar que a intervenção estatal sobre os meios de comunicação conduz a um abuso de poder que coloca em risco os direitos fundamentais do homem, não pode ser agente de perturbação ou destruição social.

Tal direito também comporta limitações, pois nenhum direito é absoluto em todos os sentidos. Nesse caminho, o magistrado não poderá se pronunciar sobre matéria submetida à sua consideração, salvo via decisão nos próprios autos, as limitações quanto a manifestações políticas no âmbito das repartições públicas, a proibição do anonimato e outras (CALDAS, 1997).

Inquietação proveniente das novas tecnologias, que permitem devassar a intimidade do homem, cabe ao Direito responder, determinando o que é lícito ou não na utilização dos novos recursos.

A liberdade de expressão e informação, consagrada em textos constitucionais sem nenhuma forma de censura prévia, constitui uma das características das atuais sociedades democráticas e, num Estado Democrático de Direito, onde as liberdades públicas são reconhecidas, desempenha um duplo papel: é informadora e formadora de opiniões.

$O$ direito à informação, como alicerce fundamental, para a preservação da verdade factual, é indispensável e requer a informação exata e honesta.

É inegável que a liberdade de expressão e informação tem desempenhado um papel de orientadora da opinião pública, o que faz dessas liberdades uma necessidade preliminar ao exercício de outros direitos fundamentais. Os tribunais constitucionais têm dado uma posição de primazia ao direito à informação, quando esse é confrontado com outros direitos fundamentais, muito embora esse destaque suscite controvérsias doutrinárias, 
pois, como todo e qualquer direito, o direito à informação possui seus limites. "A veracidade da informação se estabelece como uma imposição jurídica e moral” (AIETA, 1999, p. 183).

A compatibilização do direito à informação com outros direitos fundamentais é de extrema importância. A necessidade de frear o direito à informação, diz a autora, surge concomitante aos abusos cometidos por certos organismos de comunicação, violadores da privacidade alheia. Mas há de se analisar com extremo rigor "os freios censores”, pois serviram, inúmeras vezes, como instrumentos para o cerceamento de liberdades, por meio de censuras vis e exacerbadas, violadoras dos direitos humanos fundamentais.

No caminho do direito à informação se encontra o direito à vida privada e à intimidade como um limite extremo e vice-versa, pois ambos os casos atuam como limitadores, enquanto direitos fundamentais autônomos. A ordem jurídica ora proíbe, ora restringe, ora protege, ora incentiva, quer os comportamentos dos homens, quer as práticas de suas organizações, em nome de valores como a justiça, o bem-estar e o progresso social, interpretados à luz das concepções que a seu respeito prevalecem em cada espaço, em cada tempo. Mas, como a informação não constitui um bem de produção material, objeto típico do direito de propriedade, nem uma coisa incorpórea no sentido do direito da propriedade intelectual, tem-se a necessidade de definir qual a sua natureza e ter uma definição clara das regras do jogo do mercado da informação (GONÇALVES, 1994).

Também, a informação jornalística defronta-se com críticas à objetividade da mídia, dado que o "limite interno da veracidade, aplicado ao direito à informação, é à verdade subjetiva” (FARIAS, 2000, p. 165).

\section{CONFLITO ENTRE O DIREITO À VIDA PRIVADA E O DIREITO À INFORMAÇÃO}

A dificuldade de controle ético sobre a informação jornalística, frequentemente produz a colisão entre os direitos funda- 
mentais da intimidade e da liberdade de expressão e informação. Segundo Farias, essa colisão pode ocorrer de duas maneiras: "com a colisão entre os próprios direitos fundamentais e por meio do exercício de um direito fundamental em colisão com a necessidade de preservação de outros valores constitucionais" (AIETA, 1999, p. 183).

$\mathrm{Na}$ hipótese de choque de direitos fundamentais, como é o caso em exame, a solução pode ser encontrada em alguns critérios, tais como: o cronológico, o hierárquico e o da especialidade. ${ }^{7}$ Entre os juristas, predomina a ideia de que, em caso de conflito entre o direito à intimidade e à informação, deve-se adotar o critério hierárquico, dando prevalência ao direito à informação. Se o direito à informação não for exercido mediante fins nobres, o exercício arbitrário do direito à informação não é considerado aceitável.

O mais usual é que "[...] a colisão dos direitos fundamentais da intimidade e da liberdade de expressão e informação encontre solução, a partir da análise da importância dos princípios concorrentes no caso concreto, avaliando se o critério da razoabilidade da proporcionalidade está mais para um direito, ou para o outro" (AIETA, 1999, p. 183). Se os direitos fundamentais, não estiverem sujeitos à reserva da lei, a solução para eventual colisão "[...] fica para os juízes ou tribunais" (PEREIRA, 1996, p. 5). Nesse caso, importa observar se os direitos estão consagrados em regras e princípios, hipótese em que a solução deverá ter presente a distinção apresentada (entre princípios e regras jurídicas $)^{8}$, além de submeter-se a outras regras, tais como

7 O critério cronológico é utilizado para a solução do conflito de regras em casos em que uma sucede a outra cronologicamente; o hierárquico, quando um direito é considerado superior ao outro; e o da especialidade, é invocado para dirimir direitos incompatíveis (AIETA, 1999, p. 184).

$8 \mathrm{Na}$ perspectiva da teoria dos direitos fundamentais, desenvolvida por Robert Alexy, em Teoria de los derechos fundamentales (1997, p. 82-86), as normas de direitos fundamentais distinguem-se em normas do tipo princípio e normas do tipo regra. A Teoria de los derechos fundamentales evidencia que "o ponto decisivo para a distinção entre regras e princípios é que os princípios são 'mandados de otimização' enquanto que as regras têm o caráter de 'mandados definitivos'. Enquanto mandados de otimização, os princípios são normas que ordenam que algo seja realizado na maior medida possível, de acordo com as possibilidades jurídicas e fáticas. Isto 
a inadmissibilidade processual das provas ilícitas e o princípio alemão da proporcionalidade, que nasce a partir dos julgados dos tribunais alemães que, em casos excepcionais, admitem a prova ilícita, alegando o princípio do equilíbrio entre valores fundamentais em colisão.

Esse princípio, no direito norte-americano, encontra similaridade com o critério da razoabilidade. Aieta (1999) destaca que, não obstante o caráter subjetivo desse princípio e os riscos que podem ocorrer com sua aplicação, a doutrina tem admitido a sua utilização como mecanismo de "[...] salvaguarda e manutenção de valores conflitantes", embora de sua aplicação possa acarretar "resultados desproporcionais, desusuais e repugnantes, se inadimitida a prova ilícita colhida". Assim, no tocante às provas ilícitas que favoreçam o acusado, a doutrina é unânime em reconhecer a aplicação do princípio alemão da proporcionalidade, baseando-se no "princípio constitucional do direito de defesa". No direito brasileiro, há uma tendência evolutiva no tocante às provas ilícitas, na aplicação do princípio da proporcionalidade.

Importa ainda observar que os problemas jurídicos suscitados pela utilização da informática e pela emergência do mercado da informação são relativamente recentes e nem sempre encontram respostas claras nos quadros jurídicos existentes.

No direito à informação, em se tratando de um campo não estabilizado, vicejam observações interpretativas de tendências, algumas das quais aproveitadas neste trabalho, que oferece uma reflexão em torno de matérias fortemente dinâmicas, e por se ajustarem à evolução da tecnologia, das necessidades

significa que podem ser satisfeitos em graus diferentes e que a satisfação da medida ordenada depende não só das possibilidades fáticas senão jurídicas, que estão determinadas não só por regras, mas, também, essencialmente, pelos princípios opostos. Esse último implica que os princípios são suscetíveis de ponderação e, ademais, a necessitam. A ponderação é a forma de aplicação do direito que caracteriza os princípios. Ao contrário, as regras são normas que sempre ou bem são satisfeitas ou não o são. Se uma regra vale e é aplicável, então, está ordenado fazer exatamente o que ela exige; nada mais e nada menos. [...]. A subsunção é para elas a forma característica de aplicação do direito" (N. T., texto em espanhol, apud RIOS, 2001, p. 65). 
econômicas e da consciência social e política. Nessa perspectiva, é notório que o exercício da liberdade de expressão não pode ser confundido com o mérito das opiniões e informações divulgadas. Portanto, não há de se confundir a liberdade de expressão e informação jornalística com a ideia de violação à vida privada e à intimidade.

Um ponto decisivo nessa questão é que a determinação de âmbitos de liberdade é sempre um juízo de ponderação entre normas fundamentais. Nesse caso, para alguns, esse juízo terminará dando prioridade a um individualismo extremo; para outros, o mesmo juízo produzirá a maior gravitação dos bens coletivos.

O problema da vida privada e a liberdade de expressão é uma colisão entre princípios contraditórios, de maneira que o tratamento não discriminatório exclui a liberdade de expressão, da mesma forma que o faz a intimidade privada. A liberdade de informar, igualmente reconhecida constitucionalmente, também pode colidir frontalmente com a vida privada. $\mathrm{Na}$ busca de um ponto de equilíbrio, os tribunais têm afirmado que a liberdade de imprensa é um direito absoluto somente em um aspecto: o de não estar submetida à censura prévia. Mas seu exercício pode implicar certas responsabilidades, principalmente quando se abusa do direito de informar.

\section{CONCLUSÃO}

O desafio para a concretização de princípios contraditórios, como o direito à vida privada e à liberdade de imprensa, reside no poder de argumentação dos intérpretes da lei. Em tais casos, parece mister analisar o âmbito de alcance de cada um dos princípios envolvidos, determinando-lhes a proporcionalidade, pela função que desempenham no ordenamento e serem interpretados implícita e explicitamente, colhendo seu significado em confronto com a realidade. 
A interpretação das leis não deve ser formal, mas antes de tudo real, humana e socialmente útil. Agindo assim, estar-se-á contribuindo para a efetividade dos direitos humanos fundamentais, enquanto princípios constitucionais, pois se estará caminhando para a concretização dos mesmos.

Os direitos fundamentais são estudados enquanto direitos jurídico-positivos, uma vez vigentes numa determinada ordem constitucional, razão pela qual são coisas desejáveis, fins que merecem ser perseguidos, contudo, apesar de toda essa desejabilidade, ainda não foram totalmente reconhecidos. É importante ressaltar a sua qualidade de direitos fundamentais colocados no mais alto degrau das fontes dos direitos: as normas constitucionais. E na medida em que encontram o reconhecimento nas instituições, deles deriva consequências jurídicas. Nesse sentido, o sistema dos direitos fundamentais, constitucionalmente consagrado, é concebido como um complexo normativo hierárquico no conjunto do sistema jurídico em geral.

$\mathrm{Na}$ análise dos direitos do homem, o problema mais grave, contemporaneamente, em relação a esses direitos, consiste não mais apenas em fundamentá-los, mas protegê-los; de modo que, o problema não é filosófico, mas, sim, político.

Se a vida privada consiste na exclusão do conhecimento alheio de ideias e fatos respeitantes à própria pessoa (essência da intimidade), é pela sua tutela que se deve limitar a penetração externa no âmbito que cada um quer manter exclusivamente para si. A partir daí, entende-se que a vida privada é o direito de excluir razoavelmente da informação alheia, fatos e danos pertinentes ao sujeito.

Presente a predominância do interesse coletivo sobre o particular, cabe verificar em cada caso, o alcance respectivo. $\mathrm{Na}$ legislação brasileira, a vida privada é inviolável, e o juiz, a requerimento do interessado, deve tomar as providências necessárias ou fazer cessar o ato contrário à norma do artigo 21 do Código Civil Brasileiro de 2002. 
É imperativo que se busque a solução para a colisão entre o direito à vida privada e à informação, por meio do princípio da finalidade, que traz no seu bojo a aclamação do interesse público. Mas, para tanto, faz-se necessário que o intérprete compreenda o conteúdo dessa norma de direito fundamental violada, situado no contexto histórico concreto, sem ignorar a realidade dos fatos, a intensidade da lesão e o estágio de conhecimento relativo à realidade problematizada juridicamente.

Este esforço, por parte do intérprete, é o desafio que se coloca para solucionar o conflito entre o direito à vida privada e o da informação, os dois princípios fundamentais em choque na tela deste estudo. Ambos são normas constitucionais do tipo princípios, também são normas do tipo regra constitucional, e exigem o cumprimento exato de seu conteúdo. Analisada desse ângulo, portanto, a regra do art. 220, § 1\%, verifica-se que o exercício da liberdade de informação é limitado, tanto no âmbito constitucional como no infraconstitucional, mas, neste milênio, faz-se necessário uma ética que concilie as exigências da vida social com a proteção do direito à intimidade.

Abstract: This article addresses the issue of the right to privacy and the right to information. Your goal is to examine these rights under the Constitution of the Federative Republic of Brazil in 1988, seeking a consensus for the discussions surrounding these two fundamental principles protected in the same constitutional level. The text builds on the study on the "Right to privacy and journalistic information", using literature, sought to show the right to life and to information as fundamental rights and conflict between these rights. The study results indicated that the solution to the conflict between the right to privacy and the right to information must be sought in the Brazilian legal system and interpretation of constitutional norms.

Keywords: Collision rights. Privacy. Information. 


\section{REFERÊNCIAS}

AIETA, Vânia Siciliano. A garantia da intimidade como direito fundamental. Rio de Janeiro: Lumen Júris, 1999.

AMORIM, José Roberto Neves. Direito sobre a história da própria vida.

Revista dos Tribunais, São Paulo, ano 87, n. 749, p. 1-9, mar. 1998.

ARAÚJO, José L. Intimidade, vida privada e direito penal. São Paulo: WVC Editora, 1998.

ARDENGHI, Régis Schneider. Direito à vida privada e informação jornalística. [dissertação], Curso de Pós-Gradução Stricto Sensu em Ciência Jurídica Mestrado. Universidade do Vale do Itajaí, SC. Itajaí, 2002.

BITTAR, Carlos Alberto. Os direitos da personalidade. 7.ed. Rio de Janeiro: Forense/Universitária, 2004.

BOBBIO, Norberto. A era dos direitos. Rio de Janeiro: Campus, 2004.

BONAVIDES, Paulo. Curso de direito constitucional. São Paulo: Malheiros, 2004.

BRASIL. Constituição da República Federativa do Brasil de 1988.

. Código Civil. Lei 10.406, de 10 de janeiro de 2002.

CALDAS, Pedro Frederico. Vida privada, liberdade de imprensa e dano moral. São Paulo: Saraiva, 1997.

DOTTI, René Ariel. Proteção da vida privada e liberdade de informação. São Paulo: Ed. Revista dos Tribunais, 1990.

FARIAS, Edilsom Pereira. Colisão de direitos: a honra, a intimidade, a vida privada e a imagem versus a liberdade de expressão e informação. 2.ed. Porto Alegre: Sérgio Fabris Editor, 2000.

FERREIRA DA SILVA, Edson. Direito à intimidade.2.ed. São Paulo: Ed. Juarez de Oliveira, 2003.

GONÇALVES, Maria Eduarda. Direito da informação. Coimbra: Livraria Almedina, 1994.

GUERRA FILHO, Willis Santiago. Processo constitucional e direitos fundamentais. São Paulo: Celso Bastos, 2003. 
LAFER, Celso. A reconstrução dos direitos humanos: um diálogo com o pensamento de Hannah Arendt. São Paulo: Companhia das Letras, 1988 .

MORAES, Alexandre. Direitos humanos fundamentais: teoria geral, comentários aos arts. 1० a 5 da Constituição da República Federativa do Brasil, doutrina e jurisprudência. 3.ed. São Paulo: Atlas, 2000. (Coleção temas jurídicos; 3 ).

PEREIRA, Carlos Frederico de Oliveira. Colisão de direitos. Correio Braziliense, Suplemento Direito \& Justiça. Brasília, 12 ago. 1996.

RIOS, Roger Raupp. A homossexualidade no direito. Porto Alegre: Livraria do Advogado/ESMAFE, 2001.

SAMPAIO, José Adércio Leite. Direito à intimidade e à vida privada: uma visão jurídica da sexualidade, da família, da comunicação e informações pessoais, da vida e da morte. Belo Horizonte: Del Rey, 1998.

SARLET, Ingo Wolfrang. Dignidade da pessoa humana e direitos fundamentais na Constituição Federal de 1988. Porto Alegre: Livraria do Advogado, 2011.

SCHMITT, Carl. Teoria de la constitución. Madri: Alianza Universidad Textos, 1996.

SERRANO, Vidal. A proteção constitucional da informação e o direito à crítica jornalística. São Paulo: FTD, 1997.

SILVA, José Afonso da. Curso de direito constitucional positivo. 34.ed. São Paulo: Malheiros, 2011. 